address some of the issues would be to have a speciality tutor in general psychiatry to raise the profile for generalists, regionally and with the College.

\section{Caveat}

A suggestion has been made to combine the role of regional representative with that of speciality tutor. This was raised at the Executive and Finance Committee in December 1997 and has been taken back to faculties for comment. It has stimulated a robust debate. In our opinion it would be a shame to lose the close working relationships between representative and tutor which often gives rise to a broader spectrum of views. Although there may be some logical coherence in joining the two tasks, this amalgamation is likely to be too burdensome for a single person. particularly if our suggestions for the extended responsibilities of the tutor are accepted.

\section{References}

DEAHL, M. \& TURNER, T. (1997) General psychiatry in noman's land. British Journal of Psychiatry, 171, 6-8.

EDUCATION COMMrTTEE (1989) Recognition of Psychiatric Tutors and Others Concerned with the Provision of Postgraduate Psychiatric Education and Training. London: Royal College of Psychiatrists.

Tutors Sub-COMmrTte (1993) Role of the College Psychiatric Tutor.

Jane Garner, Regional Advisor, North East Thames (previously Regional Speciality Tutor) and *Yong Lock Ong, Regional Speciality Tutor, Old Age Psychiatry, North East Thames (previously Goodmayes Hospital, Barley Lane. Goodmayes, Essex IG3 8YB)

*Correspondence

\title{
How to pass the MRCPsych examination
}

\section{Cormac and G. Marston}

Membership of the Royal College of Psychiatrists is the main qualification needed to progress from the basic training grade (senior house officer) to higher professional training (specialist registrar) in psychiatry. The Collegiate Trainees Committee (CTC) recognises that the MRCPsych examinations may generate anxiety in candidates and require a large investment in time and personal resources. The examinations are competitive, with approximately $50 \%$ of candidates passing on each attempt. It is worthwhile preparing well the first time, by planning in advance and understanding the critical factors for success. This article aims to help trainees preparing for the MRCPsych examination.

\section{Information from the College}

Trainees should obtain the current examination curricula, regulations and information about applications soon after they commence training. by writing to the Examinations Department at the College (see Appendix).

Both parts of the examination are held in the autumn and the spring. Part I selects those candidates suitable for progression to further basic training. It comprises a multiple choice question paper (MCQ) and a clinical examination, based on a patient interview. Part I may be taken after 12 months of full-time training or the equivalent in part-time training. Unlimited attempts at the MCQ are allowed and only successful candidates proceed to the clinical examination. A maximum of four attempts are allowed at the clinical examination.

Part II is more demanding, exploring knowledge in greater breadth and depth to select candidates suitable for higher specialist training. At least 30 months psychiatric experience is required, including up to six months in another approved speciality. The examination comprises two multiple choice question papers, one on clinical subjects and one on basic sciences. The 
essay paper has four questions, one answered on a topic from general psychiatry and one on a specialist topic. The critical review paper presents an extract of a research paper with relevant questions. The clinical examination has a long case and includes management issues. A separate section examines patient management problems from any field of psychiatry. Success in all sections of Part I and Part II is a prerequisite to passing the examination.

\section{Eligibility to take the examination}

Candidates must have the relevant clinical experience and attend a College approved MRCPsych course. Allow plenty of time to fill in the application forms and for the consultant sponsors to complete their sections. If there is any doubt about eligibility to take the examination, consult your clinical tutor and write to the Examinations Department well in advance. Typical difficulties include breaks in training, overseas experience or accreditation of 'nonpsychiatric' experience. With about 500 candidates applying, please be patient with the Examinations Department. Abusive phone calls are unhelpful.

\section{Critical success factors}

Candidates' own capabilities and experience play a significant part, but do not guarantee success. Tactics are essential and to succeed you will need a combination of motivation, a supportive environment and a well-planned study programme.

\section{Motivation}

Belief in your own capabilities is very important. Focus on the positive benefits that will come from success in the examination. Programme your limbic system by reliving past successes and use self-affirmation statements to boost your morale and confidence. Encourage and reward yourself for studying.

Choose the best time for you to take the examination. Recognise that stress will affect your concentration and stamina. If you are unwell, bereaved or have a new baby, then allow yourself plenty of time to recover. Withdraw from the examination, with your tutor's support, if you feel overwhelmed or badly prepared, rather than lose an attempt.

\section{Study programme}

The time that candidates leave for revision is a personal decision but to avoid last minute panic and unproductive stress, we suggest studying for two hours per day for six months for Part I and six to 12 months for Part II. It is important not to underestimate the breadth and depth of knowledge required and the difficulty of the examination.

It is very useful to base revision on the examination curricula (Royal College of Psychiatrists, 1994), taking a section at a time, to avoid being overwhelmed by the task ahead. Some subjects. for example statistics and psychology, may take longer than anticipated to revise. We recommend arranging some study leave either for personal study or to attend a revision course. Revision courses are very intensive, so well prepared candidates will gain more. Attending six months in advance may be helpful.

A healthy balance needs to be struck between study time and other important aspects of your life. Inevitably on-call duties will interfere with revision plans so make allowances for this. Your study plan should include time for study leave and holidays. We advise against using annual leave for revision, which is unnecessary if you plan ahead. It is helpful to have a regular time of day to study when you are most likely to be alert and uninterrupted.

\section{Study skills}

To succeed you will need a large amount of information at your fingertips so start by looking at your learning techniques. Time spent on enhancing your study skills may well save time later. Perusing sections on memory in psychology textbooks and books on memory improvement (Buzan \& Buzan, 1995; Buzan, 1996) will improve your technique. Memory involves encoding information and then being able to recall it. Discover your preferred sensory inputs. Enhance your learning by combining modalities. for example reading aloud, making notes or tapes, drawing diagrams or creating Mindmaps. Mindmaps are particularly helpful for complex subjects like psychiatry as the process includes organising the information, which facilitates rapid recall.

Memory traces that are reinforced become stronger (Atkinson et al, 1990). Testing your knowledge before you begin studying activates past memory traces. New information is more likely to be laid down with the previous information, thus improving recall. Memory is better for topics learnt at the beginning and end of study periods, so short breaks will improve the efficiency of learning. Reinforce your memory traces and recall by looking over your work one hour, one day, one week and one month later.

\section{Places to study}

Arrange a suitable place for yourself to study. Having a well-lit desk or table with a comfortable 
chair is essential. Make sure the room is quiet, at a comfortable temperature and is a pleasant area, so that you enjoy being there. If you keep the room free of clutter you will be less likely to distract yourself. Use music to keep the right side of your brain occupied while you study. If possible do not revise in your bedroom. This is for more enjoyable and essential activities (sleep!).

\section{Building support networks}

At home the active support of a partner, family or friends will contribute to your success, for example, by protecting you from interruptions, or helping with essential domestic tasks.

Other candidates may be willing to form a study group with you. This may relieve some of the loneliness and tedium of studying, along with sharing knowledge and skills. Divide tasks and provide summaries of topics to reduce individual work loads.

Specialist registrars may be willing to give tutorials and mock examinations which are particularly helpful for the clinical examinations and patient management problems.

The support of your College tutor is important to ensure that you have relevant clinical experience, especially before Part II. Request a smaller clinical workload if needed. Some consultant trainers may be more understanding and supportive than others. Being criticised by colleagues or peers will knock your confidence and reduce your motivation. If someone is upsetting you, try to avoid them tactfully. If this is not possible then seek help (Cormac, 1999).

\section{Stress}

Sitting postgraduate examinations, while working, is stressful. Taking care of your health and improving your fitness makes you less likely to become ill. Any form of exercise will lift your mood, compensate for the forced inactivity of studying and improve your energy level.

Relaxation techniques may help to overcome stress. If you are tired it is best to take a few days break from revision and allow time to socialise which could be built into a reward system. As you get nearer the examination, try and avoid doing extra on-call duties, case presentations or journal clubs and conserve energy for your studies. Ensure that you are not on call in the week of the papers and the clinical. Warn your colleagues well in advance if you need to swap duties.

\section{Textbooks and other reading material}

The syllabus for the examination requires knowledge in a wide range of topics. A large, comprehensive textbook in the latest edition is essential.
Supplementary textbooks on basic sciences, psychology, phenomenology and statistics are also recommended. Recently successful colleagues may be able to suggest suitable books. Remember that this is an examination of the Royal College of Psychiatrists of the United Kingdom and the Republic of Ireland and the emphasis could be different in some American textbooks.

Textbooks with a good index are particularly useful for finding answers to multiple choice questions. Concise books (Buckley et al, 1995) are useful for rapid fact finding and for reducing any tendency to be over inclusive. The British National Formulary (British Medical Association \& Royal Pharmaceutical Society of Great Britain. 1998) may fill in spare moments in clinics when textbooks are absent.

For Part II many subjects will need to be tackled in more depth. Additional textbooks on child psychiatry, forensic psychiatry, learning disability, psychotherapy, substance misuse and pharmacology are recommended. The College Seminars series is particularly useful as some information is only readily available in these texts. Review articles in the British Journal of Psychiatry and other leading journals are good for essays. The British Journal of Hospital Medicine has articles on examination techniques and specimen questions.

\section{Practice}

Practise all sections of the examination in advance with your colleagues. Failure to do this will seriously impair your chances of passing.

\section{Multiple choice papers}

The standard of the examination varies on each occasion with no set pass mark. No one can preguess how many questions to answer but if insufficient numbers are attempted you may fail. Remember that all the MCQs are negatively marked, with one mark lost for each wrong answer, so, if you are not careful, it is quite possible to lose as many marks as you gain.

Many candidates use MCQ books and find them helpful. However, they are not necessarily the same standard as the actual examinations. It is essential to practise answering questions which are similar to the 'real' ones, so talk to recent candidates about their experiences. This will stimulate your interest and help to focus your learning. Practise doing MCQs under examination conditions to identify your strengths and weaknesses, as 'best guessing' is sometimes essential. Some MCQs are designed for the winner of the Laughlin Prize, so do not panic if you cannot answer every question. With the MCQ papers it is essential to mark the 
answers on the answer sheet as you go along. Some people like to answer all the questions which they feel confident about first, returning to those they are less sure about. If you do this, keep a careful eye on the clock.

\section{Essays}

Many people have not written an essay for years. Practice is vital, especially for those who do not have English as their first language. If you have difficulty with written English ask colleagues for advice regarding areas for improvement. One question should be answered from each section on adult psychiatry and a speciality. Current "hot topics' may be found in the British Journal of Psychiatry, the Psychiatric Bulletin, Advances in Psychiatric Treatment and in Current Opinion. Useful references to research papers can be found in textbooks, so reading many original research papers could prove an inefficient use of study time.

When writing an essay, balanced discussion as well as factual information needs to be included. It is important to formulate an essay plan and submit this along with your essay. Some candidates spend at least one third of the allotted time preparing a plan. A well-structured essay gives a much better impression and will have fewer important omissions. It is essential to write legibly so that the examiner can read your paper easily. Some candidates prefer to use double spacing, headings and underline important words. Practise making essay plans and writing essays.

\section{Critical review paper}

Candidates must read the guidance and specimen papers provided by the College. A research paper will be summarised and presented with questions about the design of the study and interpretation of the results. Questions on statistics are likely to be included, of a similar standard to previous short answer questions. The clinical relevance of the findings will probably be asked. Critical appraisal skills should be practised in journal clubs and books on evidence-based medicine are available (see College reading list).

\section{Clinical examination}

It is essential to pass the clinical examination. High marks in this section can compensate for poor marks in another paper. Mock clinical examinations are crucial and will reduce your anxiety on the day. If facilities are available, a video recording will enable you to recognise the areas which need improving. It is worth con- templating the possible range of cases in advance (e.g. patients with schizophrenia, an eating disorder, substance misuse or depression). Anticipate likely questions and practise suitable answers.

Always write down your formulation, aetiology and management plan before seeing the examiners. Use the biological, psychological, social model for aetiology, together with an appropriate time scale of predisposing, precipitating and perpetuating factors. To help structure your management plan we suggest using the headings: immediate, medium and long term.

Patient management problems for the Part II are particularly challenging. Practise them with your colleagues and give a balanced and safe perspective. Remember that it is not a failure to suggest asking others for advice.

\section{What to expect on the day}

Be quite sure that you know exactly where the examination is to be held. Plan how you will get there and allow plenty of time so that you are not in a rush (people are late every year for a variety of reasons!). If you have to stay overnight, select comfortable accommodation so that you sleep well. Avoid the temptation to consume alcohol, stimulants or sedatives. If you have practised all parts of the examination in advance, this will reduce your anxiety. Control your anxiety by psychological methods such as relaxation, self-distraction and cognitivebehavioural techniques. In the clinical, reassure yourself that the examiners are looking for candidates who will make good specialist registrars.

\section{Summary}

There can be no doubt that the whole process may be very stressful, but by covering all the areas in the curricula and practising all the different parts of the examination, you will have increased your chances considerably. Remember one slip up does not automatically mean failure and good marks in the clinical may compensate for poor marks in a paper. Approximately one in two people pass ... so why not you?

\section{Appendix}

Ask other doctors who have recently taken the examination for their recommendations.

The address of the Royal College of Psychiatrists: 17 Belgrave Square, London SW1X 8PG. 
The College Seminars series can be obtained from the College Publications Department by post.

Apply to become an Inceptor of the College, to receive the British Journal of Psychiatry and the Psychiatric Bulletin, and information about College meetings. Inceptors are also eligible to join the Collegiate Trainees Committee and receive The Inceptors Handbook, which has useful advice for trainees on several topics.

Obtain articles from the British Journal of Hospital Medicine on examination techniques and specimen questions for both parts of the examination.

\section{Acknowledgements}

We thank all members of the Collegiate Trainees Commitee for their contributions and the Dean of the College, Professor Cox, for his advice and encouragement. We are grateful to Dr M. Atkins and Dr R. Thavasothy for their comments on the paper.

\section{References}

AtKinson, R., ATKinson, R., SMrth, E.. et al (1990) Introduction to Psychology. pp. 288-329. Orlando. FL: Harcourt-Brace College Publishers.

BRtTSH Medical Association \& The Royal Pharmaceutical SOCIETY OF GREAT BRTTAN (1998) British National Formulary (Number 36. September 1998). London: British Medical Association and the Royal Pharmaceutical Society of Great Britain.

BUCKLEY, P., BIRD, J. \& HARRISON, G. (1995) Examination Notes in Psychiatry: A Postgraduate Text. Oxford: Butterworth-Heinman Ltd.

Buzan, T. (1996) Use Your Head (ed. V. North). London: BBC Worldwide Publishing.

- \& BUZAN. B. (1995) The Mind Map Book. London: BBC Books.

MARSTON, G. \& CORMAC, I. (1999) The Collegiate Trainees Committee: Guidance for Trainees Having Interpersonal Problems with Their Educational Supervisor. Psychiatric Bulletin, 23, 43.

Royal COLLEGE OF PSYCHIATRISTS (1994) The Basic Sciences and Clinical Curricula for the MRCPsych Examination. London: Royal College of Psychiatrists.

I. Cormac, Specialist Registrar, Coventry Mental Healthcare NHS Trust, The Caludon Centre, Clifford Bridge Road, Coventry CV2 2TE and G. Marston, Senior Registrar, Brooklands, Coleshill Road, Marston Green B37 7HL

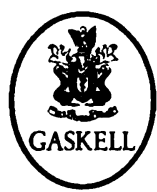 \\ Child Psychiatry and the Law (3rd edn)}

\section{Edited by Dora Black, Jean Harris Hendriks and Stephen Wolkind}

This informative text covers all aspects of child psychiatry in the legal world. It offers excellent and carefully presented new material which will prove invaluable both to practitioners new to medico-legal work and to those more experienced. This edition has been revised and updated to take account of the developing practice and legal decisions since the implementation of the Children Act 1989 England and Wales. A framework for the provision of expert evidence on behalf of children, in the private and public civil law, has been approved by the official solicitor to the supreme court.

December 1998, 250pp, Paperback, ISBN 190124214 5, £20.00

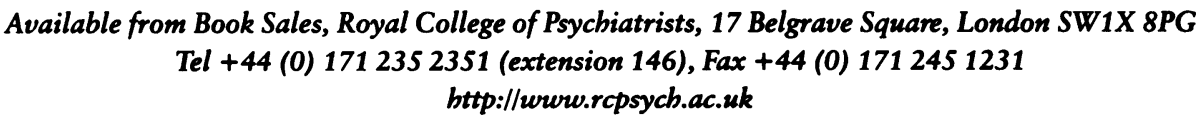

Available from Book Sales, Royal College of Psychiatrists, 17 Belgrave Square, London SW1X 8PG Tel +44 (0) 1712352351 (extension 146), Fax +44 (0) 1712451231

bttp://wrww.rcpsych.ac.uk 